the family should also be examined. It would appear that the clinical expression of the condition may be variable, and even non-penetrance may be encountered.

\section{REFERENCES}

Albanese M, Pizzutillo PD. Family study of spondylolysis and spondylolisthesis. J Pediatr Orthop 1982:2:496-99.

Amuso SJ, Mankin HJ. Hereditary spondylolisthesis and spina bifida: report of a family in which the lesion is transmitted as an autosomal dominant through three generations. J Bone Joint Surg [Am] 1967:49-A:507-13.

Dawley JA. Spondylolisthesis of the cervical spine: case report. $J$ Neurosurg 1971:34:99 101.
Eldridge R. The metacarpal index: a useful aid in the diagnosis of the Marfan syndrome. Arch Intern Med 1964:113:248-54.

Fardon DF, Fielding JW. Defects of the pedicle and spondylolisthesis of the second cervical vertebra. J Bone Joint Surg [Br] 1981;63-B: $526-8$.

Haukipuro K, Keränen N, Koivisto E, Lindholm R, Norio R, Punto L. Familial occurrence of lumbar spondylolysis and spondylolisthesis. Clin Genet 1978;13:471-6.

Rand TC, Edwards DK, Bay CA, Jones KL. The metacarpal index in normal children. Pediatr Radiol 1980:9:31 2.

Taillard WF. Etiology of spondylolisthesis. Clin Orthop 1976;117: 309.

Wiltse LL, Newman PH, Macnab I. Classification of spondylolisis and spondylolisthesis. Clin Orthop 1976;117:23-9.

BRIEF REPORT

\title{
SCIATICA CAUSED BY PERIFIBROSIS OF THE SCIATIC NERVE
}

\section{ULRIK MERRILD, IB SØGAARD}

Case report. A 39-year-old man was admitted with a history of right sciatica without pain in his back. He had never had symptoms from his back or legs until six months earlier when he fell two metres into a pit, landing on his right buttock. Since then he had had right sciatica extending down to the outer aspect of the ankle after sitting for more than 10 minutes. Conservative treatment had no effect. On admission he had reduced sensation to touch and to pain on the lateral aspect of his right calf and in the first dorsal web space of his foot, slight weakness of dorsiflexion of his ankle and hallux, a positive Lasègue's sign at 60 , and a positive Tinel sign over the sciatic nerve in the mid-thigh. The tendon reflexes were normal. Radiographs of his lumbosacral spine showed spondylolisthesis at $\mathrm{L} 4 / 5$, with only slight forward slip. Myelography demonstrated slight shortening of the right fifth lumbar nerve root.

At exploration through a right partial hemilaminectomy no intervertebral laxity was demonstrated and there was no disc herniation. Three weeks after this operation his symptoms recurred and once again conservative treatment had no effect. When he was readmit-

U. Merrild, MD, Surgeon

1. Søgaard. MD. Chief Surgeon

Department of Neurosurgery. The University Hospital of Odense, DK-5000, Odense C. Denmark.

Correspondence to Dr Merrild.

- 1986 British Editorial Society of Bone and Joint Surgery $0301620 \mathrm{X} / 86 / 5 \mathrm{RO} 2 \$ 2.00$ ted three months later, his signs, including the positive Tinel sign, were unchanged. A CT scan of the lumbar spine showed no disc herniation. Electromyography supported the clinical suspicion of damage to the sciatic nerve itself, with a partial block to conduction. At operation the nerve was found to be surrounded by tight fibrosis in the gluteal region and was decompressed.

Six months later the patient had resumed his job as a policeman. His signs and symptoms had subsided, leaving only slight wasting of the thigh; the Tinel sign and the Lasègue sign were both negative.

Discussion. Sciatic nerve damage causing pain radiating distally is unusual (see references). The following characteristics should arouse suspicion: a history of direct trauma to the nerve; aggravation of symptoms when pressure is applied, for example, by sitting; a positive Tinel sign; exclusion of a herniated disc by myelography or CT scan; and an electromyogram compatible with a sciatic nerve block. None of these findings is specific and a definitive diagnosis can only be achieved if, at operation, the nerve is found to be compressed and if signs and symptoms subside after decompression. Electromyography is probably the most useful diagnostic aid.

\section{REFERENCES}

Banerjee T, Hall CD. Sciatic entrapment neuropathy: case report. $J$ Neurosurg 1976;45:216-7.

Richardson RR, Hahn YS, Siqueira EB. Intraneural hematoma of the sciatic nerve: case report. J Neurosurg 1978:49:298-300.

Segaard I. Sciatic nerve entrapment: case report. J Neurosurg 1983:58: 2756. 